\title{
AUTENTIČNOST RODITELJA
}

Cilj istraživanja je bio utvrditi da li postoji povezanost između autentičnosti roditelja i njihove autentičnosti u partnerskom odnosu, dužine braka, broja dece, prosečnog uzrasta dece, zadovoljstva partnerskim odnosom i podrškom partnera. Uzorak su činila 32 bračna para koji su ostvareni u ulozi roditelja $(\mathrm{N}=64)$. Ispitivana je autentičnost roditelja i njihova autentičnost u partnerskom odnosu. Rezultati su pokazali da će se roditelji, što su deca mlađa i što su sami zadovoljniji partnerskim odnosom i podrškom partnera, pre ponašati u skladu sa pravim ja (visok autentični život) i slobodnije će pokazivati svoje misli, emocije, potrebe i težnje partneru (autentičnost u partnerskom odnosu). Takođe, rezultati pokazuju da su roditelji manje autentični u partnerskom odnosu ukoliko više prihvataju spoljašnje uticaje (visoko prihvatanje spoljašnjih uticaja) i sebe ubeđuju da su želje i vrednosti drugih ustvari njihove (visoka samootuđenost). Samo roditelj koji zna kako da uskladi izražavanje svojih misli, emocija, motiva i želja sa zahtevima sredine moći će da vaspitava iskreno, slobodno i samopouzdano dete.

Ključne reči: autentičnost, roditelji, deca, zadovoljstvo partnerskim odnosom, zadovoljstvo podrškom partnera

\section{UVOD}

A. Maslov je smatrao da se autentičnost javlja kada osoba otkrije svoju pravu unutrašnju prirodu i kada ostvari svoje lične potencijale kroz zadovoljenje psiholoških potreba pri čemu je cilj autentična samoaktualizovana osoba (Goldman\&Kernis, 2002). Autentičnost nije motivisana pobunom ili kompulzivnom potrebom za nezavisnošću, nego izražavanjem unutrašnjeg ja koje je u skladu sa osnovnim potrebama drugih. Prema mišljenju C. R. Rodžersa (1961), ljudi su skloni osećanju samootuđenosti koje je najčešće rezultat sopstvenog doživljaja da lično iskustvo i dnevne aktivnosti ne potiču iz pravog ja, odnosno da nisu utemeljene u autentičnosti osobe. Ponekad pojedinac dolazi do momenta u kom ubeđuje sebe da su želje i vrednosti drugih u stvari njegove. Tada ne oseća povezanost sa ,ličnim“ vrednostima, što se kasnije izražava kroz ,stvarno ne poznajem sebe“. Autentičnost se nalazi u

\footnotetext{
djurdja.grijak@gmail.com
} 
samoj ličnosti kao dinamički proces u kom se lični potencijali, osobine, emocije, motivi i drugo otkrivaju, istražuju, prihvataju, prožimaju smislom i značenjem, i ostvaruju (Rogers, 1961). U mnogim vodećim perspektivama psihološkog savetovanja autentičnost se posmatra kao osnovni aspekt mentalnog zdravlja (Horney, 1951; Rogers, 1961; Winnicott, 1965; Yalom, 1980), što su kasnije potvrdila i druga istraživanja (Wood et al., 2008; Grijak, 2017b).

U humanističkoj koncepciji autentičnost je kao trodelni konstrukt definisala G. T. Baret-Lenard (Barrett-Lennard, 1998). Ovaj konstrukt uključuje usklađenost između tri nivoa osobe - (a) lično iskustvo (pravo ja uključujući trenutno psihičko stanje, emocije i uverenja), (b) simboličku svesnost (iskustvo predstavljeno u kognitivnoj sferi) i (c) spoljašnje ponašanje i komunikaciju. Ljudi su u osnovi društvena bića i time su i samootuđenost $i$ autentični život pod uticajem društvene sredine (Schmid, 2005). Prihvatanje perspektiva drugih i prihvatanje spoljašnjih uticaja deluje na osećanja samootuđenosti i na iskustvo autentičnog življenja. Svi aspekti zajedno stvaraju trodelni konstrukt i humanističku perspektivu autentičnosti koja pruža najšire i najjasnije objašnjenje autentičnosti. Ranija istraživanja su pokazala da ovako definisana autentičnost ne zavisi ni od pola ni od starosti ispitanika (Grijak, 2017a).

Manifestovanje autentičnosti može rezultirati ozbiljnim socijalnim sankcijama (Wood et al., 2008). Očekuje se da autentičnost odražava usklađenost između pravog ja i zahteva sredine, ali i svesti o potencijalnim posledicama individualnih izbora $u$ ponašanju. Autentičnost se ne ogleda u potrebi da se bude pravo ja, nego u slobodnom i prirodnom izražavanju vlastitih emocija, motiva i težnji. Kada je ovako shvaćena autentičnost $u$ suprotnosti sa socijalnim situacijama i ulogama, postoji mogućnost za kratkotrajni konflikt. Istraživanja u oblasti socijalne psihologije su pokazala da je autentičnost osobe povezana sa njenim socijalnim ulogama (Wood et al., 2008). Autentičnost je negativno povezana sa anksioznošću, stresom i depresijom, a pozitivno povezana sa samopouzdanjem na šta je, delom, uticala i različitost socijalnih uloga osobe i njenog subjektivnog blagostanja. Osobe koje imaju više različitih uloga procenjuju da su manje autentične, odnosno da se ređe ponašaju u skladu sa pravim $j a$, što podrazumeva dimenziju autentičnog života (Sheldon et al., 1997). Za ispitivanje autentičnosti u partnerskom odnosu razvijena je prilično rigidna mera autentičnog života i prihvatanja spoljašnjih uticaja, a rezultati su pokazali da postoji povezanost između ovih dimenzija i samopouzdanja, depresije, anksioznosti i zadovoljstva životom, ali i povezanost između autentičnosti i zadovoljstva partnerskim odnosom (Lopez\&Rice, 2006). U ovom istraživanju nije ispitivana samootuđenost kao dimenzija autentičnosti osobe. Istraživanja koja su sprovedena kod nas pokazala su da su prihvatanje spoljašnjih uticaja i samootuđenost 
u pozitivnoj korelaciji sa psihološkim distresom (Grijak, 2017a), dok je autentičnost u partnerskom odnosu u pozitivnoj korelaciji sa samopouzdanjem, zadovoljstvom podrškom partnera, partnerskim odnosom i autentičnim životom, a u negativnoj korelaciji sa prihvatanjem spoljašnjih uticaja i samootuđenošću (Grijak, 2018).

Mnoge studije o autentičnosti pokazale su da ispitanici mogu da prepoznaju svoje autentično i neautentično ponašanje u odnosima sa drugim ljudima, da se osećaju autentično u odnosu sa jednom osobom i neautentično u odnosu sa drugom osobom, te da razumeju da je njihovo (ne)autentično ponašanje u vezi sa različitim iskustvima u odnosima sa drugim ljudima, strategijama rešavanja konflikta i ishodima (Snyder, 1987; Lopez \& Rice, 2006). Autentično ponašanje pojedinca je uobičajeno u kontekstu emocionalno značajnih odnosa (porodica, partneri, bliski prijatelji), što ukazuje na to da spremnost na autentičnost može biti ključni faktor bliskih odnosa u kojima ljudi teže međusobnoj razmeni i proceni autentičnosti.

Samo autentičan roditelj mogao bi da prepozna i neguje autentičnost kod svog deteta. Ako roditelj ne ume da sluša dete, da mu dozvoli da izrazi svoje želje, misli i emocije, da ga usmeri na topao način da ostvari svoje ciljeve, rezultat može biti nametnuta ličnost umesto autentične (Grijak, 2017c). Iako dete ne može u potpunosti da odustane od svojih želja i interesovanja, ipak bi moglo da ih potisne i negira. Postoji mogućnost da dete tada prestane da veruje u sebe i počne da veruje $u$ to da mora da ispuni roditeljska očekivanja i bude ono što oni žele. Roditelji koji se u vaspitanju vode idejom da je dobro dete ono koje je poslušno povećavaju šanse detetu da odraste u osobu koja je poslušna, neautentična i niskog samopoštovanja i koja se povinuje mišljenjima drugih kojima je verovala više nego sebi. Na drugoj strani, mogu biti deca koja će se buniti i koristiti razne mehanizme koji će forsirati suprotnosti roditeljskim željama. Međutim, suprotstavljanje nije slobodno ponašanje nego samo suprotnost poslušnosti. Dete koje se bori da ostvari suprotno od roditeljskih očekivanja obično neće dobiti njihovu podršku, što mu umanjuje šanse da stekne poverenje u svoje sposobnosti. Kao rezultat može nastati potisnuta autentičnost koja ostaje kao neintegrisani deo ličnosti, kao zaostatak nekadašnjih detetovih potencijala i javlja se samo kroz fantaziju. Kada dete odraste u osobu uspešnu po svim merilima drugih, potisnuta autentičnost se može manifestovati kao osećaj praznine i nedostajanja nečeg nedefinisanog.

Iz svega navedenog jasno proizilazi značaj istraživanja autentičnosti roditelja koje, prema našim saznanjima, do sada u našoj sredini nije sprovedeno. Cilj sprovedenog istraživanja je bio da utvrdimo postoji li povezanost između autentičnosti roditelja i njegove autentičnosti u partnerskom odnosu, dužine braka, broja dece, prosečnog uzrasta dece, zadovoljstva bračnim odnosom i podrškom partnera. 


\section{METODOLOGIJA}

Uzorak

Uzorak za ovo istraživanje činila su 32 bračna para koji su ostvareni u ulozi roditelja $(\mathrm{N}=64)$, prosečne starosti 40 godina. Dužina braka ispitanika se kretala od 4 do 33 godine ( $\mathrm{AS}=15.71 ; \mathrm{SD}=7.55)$. Bračni parovi su u proseku imali po dvoje dece, čiji je prosečan uzrast bio 10 godina $(\mathrm{AS}=10.44 ; \mathrm{SD}=5.72)$.

\section{Procedura i postupak}

Istraživanje je sprovedeno među roditeljima dece koja su pohađala Predškolsku ustanovu „Dragoljub Udicki“ u Kikindi i Predškolsku ustanovu „Dečja radost“" u Pančevu tokom 2017. godine. Anketiranje je bilo pismeno. Ispitanici su na dobrovoljnoj osnovi učestvovali u istraživanju. Prethodno im je objašnjen cilj istraživanja kao i mogućnost da mogu odustati kada žele. Dobijeni podaci su obrađeni u statističkom programu SPSS 17. Od statističkih analiza, sproveden je Pirsonov koeficijent korelacije.

\section{Instrumenti}

Autentičnost u partnerskom odnosu. U istraživanju ove komponente ličnosti korišćena je Skala autentičnosti u partnerskom odnosu (Grijak, 2018). Ona se sastoji od 22 tvrdnje na koje ispitanici odgovaraju subjektivnom procenom zakružujući brojeve od 1 (uopšte me ne opisuje) do 9 (vrlo dobro me opisuje), u zavisnosti od toga koliko ih ta tvrdnja opisuje. Skala sadrži dve subskale neprihvatanje obmane $(\square=.79,12$ tvrdnji) i preuzimanje intimnog rizika $(\square=.76,10$ tvrdnji). Sve stavke subskale neprihvatanje obmane rekodiraju se tako da viši rezultati ukazuju na veću, a niži na nižu autentičnost u ponašanju. $U$ ranijem istraživanju psihometrijske validacije srpske adaptacije originalne Skale autentičnosti u partnerskim odnosima (Authenticity in Relationships Scale-AIRS; Lopez\&Rice, 2006) pokazalo se da je ta skala instrument sa zadovoljavajućim psihometrijskim karakteristikama, kojim se procenjuju dve međusobno povezane dimenzije autentičnosti u partnerskim odnosima: neprihvatanje obmane i prihvatanje intimnog rizika (Grijak, 2018).

Autentičnost. U istraživanju ove komponente ličnosti korišćena je Skala autentičnosti (Grijak, 2017a). Ona se sastoji od 12 tvrdnji na koje ispitanici odgovaraju subjektivnom procenom opredeljujući se za brojeve od 1 (uopšte me ne opisuje) do 7 (vrlo dobro me opisuje), u zavisnosti od toga koliko ih ta tvrdnja 
opisuje. Skala sadrži tri subskale - autentični život $(\square=.64,4$ tvrdnje), prihvatanje spoljašnjih uticaja ( $\square=.84,4$ tvrdnje) i samootuđenje ( $\square=.78,4$ tvrdnje). Subskala autentični život ispituje u kojoj meri osoba usklađuje svoje ponašanje i emocije sa svojim uverenjima, vrednostima i trenutnim psihološkim stanjima. Subskala prihvatanje spoljašnjih uticaja pokazuje ispitanikovo uverenje da mora da ispuni očekivanja okoline. Subskala samootuđenje ispituje koliko ispitanik poznaje sebe, svoje vrednosti i uverenja. U ranijem istraživanju psihometrijske validacije srpske adaptacije originalne Skale autentičnosti (Authenticity scale - Wood et al., 2008) pokazalo se da je ta skala instrument sa dobrim psihometrijskim karakteristikama, kojim se procenjuju tri posebne, ali visoko povezane komponente autentičnosti: autentični život, prihvatanje spoljašnjih uticaja i samootuđenje u čijoj osnovi se nalazi faktor autentičnosti (Grijak, 2017a).

Procena zadovoljstva partnerskim odnosom. U istraživanju ove pojave korišćena je jednoajtemska Procena zadovoljstva partnerskim odnosom (Grijak, 2018). Ispitanici su procenjivali svoje zadovoljstvo partnerskim odnosom na petostepenoj skali od 1 (uopšte nisam zadovoljan/na) do 5 (u potpunosti sam zadovoljan/na).

Procena zadovoljstva podrškom partnera. I u ovom istraživanju korišćena je jednoajtemska Procena zadovoljstva podrškom partnera (Grijak, 2018) kojom su ispitanici procenjivali svoje zadovoljstvo podrškom partnera na petostepenoj skali od 1 (uopšte nisam zadovoljan/na) do 5 (u potpunosti sam zadovoljan/na).

\section{REZULTATI}

U tabeli 1 su prikazani rezultati deskriptivne statistike svih varijabli.

Tabela 1. Deskriptivna statistika

\begin{tabular}{lcc}
\hline & AS & SD \\
\hline Dužina braka & 15.71 & 7.55 \\
Broj dece & 1.97 & .77 \\
Prosečan uzrast dece & 10.45 & 5.71 \\
\hline Zadovoljstvo partnerskim odnosom & 4.31 & .99 \\
Zadovoljstvo podrškom partnera & 4.42 & .99 \\
Neprihvatanje obmane & 62.95 & 20.96 \\
Preuzimanje intimnog rizika & 78.87 & 13.04 \\
Autentični život & 24.57 & 3.61 \\
Prihvatanje spoljašnjih uticaja & 10.56 & 5.99 \\
Samo-otuđenost & 11.33 & 10.59 \\
\hline
\end{tabular}


U tabeli 2 su prikazani rezultati Pirsonovog koeficijenta korelacije između svih varijabli.

Tabela 2. Pirsonov koeficijent korelacije

\begin{tabular}{|c|c|c|c|c|c|c|c|}
\hline & 1 & 2 & 3 & 4 & 5 & 6 & 7 \\
\hline 1. ZPO & 1 & $.73 * *$ & $.29 *$ & $.29 *$ & $.29 *$ & -.14 & -.13 \\
\hline 2. ZPP & $.73 * *$ & 1 & .21 & .17 & $.29 *$ & -.07 & -.05 \\
\hline 3. NO & $.29 *$ & .21 & 1 & $.44 * *$ & $-.44 * *$ & $.49 * *$ & $.33 * *$ \\
\hline 4. PIR & $.29 *$ & .18 & $.44 * *$ & 1 & $.41 * *$ & $-.19 *$ & .15 \\
\hline 5. A $\mathbf{A Z}$ & $.29 *$ & $.29 *$ & $-.44 * *$ & $.41 * *$ & 1 & $-.28 *$ & -.21 \\
\hline 6. PSU & -.14 & -.06 & $.49 * *$ & -.19 & $-.28 *$ & 1 & $.29 *$ \\
\hline 7. SO & -.13 & -.05 & $.33 * *$ & -.15 & -.21 & $.29 *$ & 1 \\
\hline DB & -.03 & -.03 & -.11 & -.18 & -.18 & -.06 & -.11 \\
\hline BD & -.11 & -.13 & .16 & .06 & .17 & -.01 & -.03 \\
\hline PUD & -.22 & -.21 & $-.35 * *$ & -.22 & $-.39 * *$ & .08 & -.03 \\
\hline
\end{tabular}

Napomena: $N=64 ; * p<.05 ; * * p<.01 ; Z P O-$ zadovoljstvo partnerskim odnosom; ZPP zadovoljstvo podrškom partnera; $N O$ - neprihvatanje obmane; PIR - preuzimanje intimnog rizika; $A \check{Z}$ - autentični život; PSU - prihvatanje spoljašnjih uticaja; SO - samo-otuđenost; $D B$ - dužina braka; $B D$ - broj dece; PUD - prosečan uzrast dece.

Rezultati pokazuju da nijedna dimenzija autentičnosti nije statistički značajno povezana sa dužinom braka ispitanika niti sa brojem dece. Autentičnost $u$ partnerskom odnosu je u pozitivnoj korelaciji sa zadovoljstvom partnerskim odnosom, a procena vlastitog neprihvatanja obmane je u negativnoj korelaciji sa prosečnim uzrastom dece. Autentični život kao dimenzija autentičnosti je u pozitivnoj korelaciji sa zadovoljstvom partnerskim odnosom i zadovoljstvom podrškom partnera i u negativnoj korelaciji sa prosečnim uzrastom dece. Dimenzije autentičnosti su u korelaciji sa dimenzijama autentičnosti u partnerskom odnosu. Neprihvatanje obmane je $\mathrm{u}$ negativnoj korelaciji sa autentičnim životom, a u pozitivnoj korelaciji sa prihvatanjem spoljašnjih uticaja i samootuđenošću. Preuzimanje intimnog rizika je u pozitivnoj korelaciji sa autentičnim životom i negativnoj korelaciji sa prihvatanjem spoljašnjih uticaja. 


\section{DISKUSIJA}

Cilj istraživanja je bio da se utvrdi postoji li povezanost između autentičnosti osobe i njene autentičnosti u partnerskom odnosu, dužine braka, broja dece, prosečnog uzrasta dece, zadovoljstva bračnim odnosom i podrškom partnera. Uzorak su činila 32 bračna para koji su ostvareni u ulozi roditelja $(\mathrm{N}=64)$, prosečne starosti 40 godina. Dužina braka ispitanika je bila od 4 do 33 godine (AS=15.71; $\mathrm{SD}=7.55)$. Prosečan broj dece po bračnom paru je dvoje, a prosečan uzrast dece 10 godina ( $\mathrm{AS}=10.44 ; \mathrm{SD}=5.72$ ). U istraživanju su kao instrumenti korišćeni Skala autentičnosti u partnerskom odnosu (Grijak, 2018); Skala autentičnosti (Grijak, 2017a); srpska adaptacija jednoajtemske Procene zadovoljstva partnerskim odnosom (Grijak, 2018) i srpska adaptacija jednoajtemske Procene zadovoljstva podrškom partnera (Grijak, 2018).

Rezultati pokazuju da autentičnost roditelja nije povezana ni sa dužinom braka niti sa brojem njihove dece. Što su deca mlađa i što su zadovoljniji partnerskim odnosom i podrškom partnera, roditelji će se pre ponašati u skladu sa realnošću (visok rezultat na subskali autentični život) i slobodnije će pokazivati svoje misli, emocije, potrebe i težnje partneru (autentičnost u partnerskom odnosu). Ovim se potvrđuju prethodna istraživanja koja su pokazala pozitivnu korelaciju između autentičnog života $i$ autentičnosti u partnerskom odnosu (Lopez\&Rice, 2006; Grijak, 2018). S druge strane, rezultati pokazuju da su roditelji manje autentični kao osobe i manje autentični u partnerskom odnosu što su deca starija, ali i da su manje autentični u partnerskom odnosu što više prihvataju spoljašnje uticaje (visok rezultat na subskali prihvatanje spoljašnjih uticaja) i sebe ubeđuju da su želje i vrednosti drugih, u stvari njihove (visok rezultat na subskali samootuđenost). Dakle, što su deca starija, roditelji, iako baziraju svoj odnos na osećaju međusobne sigurnosti i poverenja (visok rezultat na subskali neprihvatanje obmane), skloni su negativnim emocijama, životu prema očekivanjima drugih ljudi i nepoznavanje sebe dovoljno, čime se potvrđuju rezultati ranijih istraživanja (Grijak, 2018). Roditelj koji ne oseća povezanost sa svojim vrednostima to može da izrazi kroz „stvarno ne poznajem sebe“ (Rogers, 1961), što može da se odrazi i na ponašanje u roditeljskoj ulozi.

Sprovedeno istraživanje je značajno budući da je prvo koje se bavilo autentičnošću roditelja kod nas. Ipak, ima nekoliko ograničenja koja se prvenstveno odnose na ispitivane varijable. Nije ispitivana autentičnost roditelja $u$ drugoj socijalnoj ulozi, npr. prijateljskoj ili profesionalnoj kako bi se utvrdilo u kojoj meri različitost socijalnih uloga utiče na autentičnost osobe, niti je ispitivan broj različitih socijalnih uloga. Uz navedene varijable, u narednim istraživanjima mogla 
bi se ispitati povezanost autentičnosti svoje i partnerove sa samopouzdanjem, zadovoljstva životom i drugih dimenzija mentalnog zdravlja ispitanika.

Roditeljstvo je jedan od izazova za autentičnost osobe i njenu autentičnost $u$ partnerskom odnosu. Samo roditelj koji zna kako da uskladi izražavanje svojih misli, emocija, motiva i želja sa zahtevima drugih, a da ih pri tome ne ignoriše, ne potiskuje niti zamenjuje socijalno poželjnim ponašanjima, moći će da vaspitava iskreno, slobodno i samopouzdano dete. Na osnovu svih iznetih rezultata možemo da zaključimo da se međusobno prožimaju autentičnost roditelja kao osobe i njegova/njena autentičnost u partnerskom odnosu. Time se potvrđuju istraživanja koja su pokazala da je autentično ponašanje pojedinca uobičajeno u kontekstu emocionalno značajnih odnosa (porodica, partneri, bliski prijatelji), što ukazuje na to da spremnost na autentičnost može biti ključni faktor bliskih odnosa u kojima ljudi teže međusobnoj razmeni i proceni autentičnosti (Lopez\&Rice, 2006; Grijak, 2018). Ovo istraživanje je pokazalo da se autentičnost roditelja menja sa odrastanjem dece čime se može potvrditi i da je autentičnost dinamički proces $u$ kom se lični potencijali, osobine, emocije, motivi i drugo otkrivaju, istražuju, prihvataju, prožimaju smislom i značenjem, i ostvaruju u odnosu sa decom kao i sa drugim ljudima (Rogers, 1961).

Đurđa Grijak

\section{AUTHENTICITY OF PARENTS}

\section{Summary}

The aim of this research was to determine whether there is a connection between the authenticity of a parent and his/her authenticity in relationship, the length of marriage, the number of children, the average age of the children, the satisfaction with relationship, and the satisfaction with a partner's support. The sample consisted of 32 married couples who were parents $(\mathrm{N}=64)$. The authenticity of parents and their authenticity in their relationship was the subject of research. The results show that parents who have younger children and are more satisfied with their relationship and their partner's support will live in accordance with reality (high Authentic life), and will freely, openly and naturally show their emotions, thoughts, and needs to their partners (Authenticity in relationship). Also, the results show that parents are less authentic in relationship if they accept external influences and convince themselves that all wishes and values from other people are their own (high Self-alienation). The results also show that the authenticity of the parents is not related to either the length of the marriage or the number of their children. A parent who thinks, but does not feel connected with his/her values, can express this through "I do not really know myself" (Rogers, 1961), which can also be reflected in the parental role. The child of such a parent 
could begin to suppress its own authenticity still in childhood and can grow into an inauthentic adult with a sense of emptiness. The authenticity of the parent as a person and his/her authenticity in a relationship are interwoven with each other, which is confirmed by the research that showed that the authentic behavior of the individual is normal in the context of emotionally significant relationships (families, partners, close friends) indicating that the readiness to be authentic could be a key factor for close relationships in which people strive for mutual exchange and the assessment of authenticity (Lopez \& Rice, 2006; Grijak, 2018). This research has shown that the authenticity of parents changes with the growth of children, which might confirm that authenticity is a dynamic process where personal potentials, traits, emotions, motives, and other things are discovered, explored, accepted, interwoven with meaning, which are then realized (Rogers, 1961). Only a parent who knows how to balance the expression of their own thoughts, emotions, motives and wishes with the demands of the environment, not neglecting them, who does not suppress or substitute them for socially desirable behaviors, will be able to nurture a happy, free and confident child.

Key words: authenticity, parent, satisfaction with relationship, satisfaction with partner's support

\section{LITERATURA}

Barrett-Lennard, G. T. (1998). Carl Rogers' helping system: Journey and substance. London: Sage.

Goldman, B. M., Kernis, M. H. (2002). The role of authenticity in healthy psychological functioning and subjective well-being. Annals of the American Psychotherapy Association, 5, 18-20.

Grijak, Dj. (2017a). Psychometric evaluation of the Authenticity Scale on the sample of students in Serbia. Psihologija, 50(1): 85-99.

Grijak, Đ. (2017b). Authenticity as a predictor of mental health. Klinička psihologija, 10, 1-2, pp. 23-34.

Grijak, Đ. (2017c). Roditelji i autentičnost predškolskog deteta. U: Svakodnevni život deteta - zbornik radova. Novi Sad : Visoka škola strukovnih studija za obrazovanje vaspitača. str.115-122.

Grijak, Đ. (2018). Validacija srpske adaptacije Skale autentičnosti u partnerskim odnosima (AIRS). Primenjena psihologija, XI/1, str.87-102.

Horney, K. (1951). Neurosis and human growth. London: Routledge.

Lopez, F. G., Rice, K. G. (2006). Preliminary development and validation of a measure of relationship authenticity. Journal of Counseling Psychology, 53: $362-371$. 
Rogers, C. R. (1961). On becoming a person: A therapist's view of psychotherapy. London: Constable.

Sheldon, K. M., Ryan, R. M. Rawsthorne, L. J., \& Ilardi, B. (1997). Trait self and true self: Cross-role variation in the Big-Five personality traits and its relations with psychological authenticity and subjective well-being. Journal of Personality and Social Psychology, 73, 1380-1393. doi:10.1037/00223514.73.6.1380

Schmid, P. F. (2005). Authenticity and alienation: Towards an understanding of the person beyond the categories of order and disorder. In S.Joseph \& R. Worsley (Eds.), Person-centred psychopathology. Ross-on-Wye, England: PCCS Books.

Snyder, M. (1987). Public appearances/private realities: The psychology of selfmonitoring. New York: Freeman.

Winnicott, D. W. (1965). The maturational processes and the facilitating environment. New York: International Universities Press.

Wood, A.M., Linley, P.A., Maltby, J., Baliousis, M., \& Joseph, S. (2008). The authentic personality: A theoretical and empirical conceptualization and the development of the Authenticity Scale. Journal of Counseling Psychology 55(3), 385-399. doi: 10.1037/0022-0167.55.3.385

Yalom, I. D. (1980). Existential psychotherapy. New York: Basic Books. 
РОМАНИСТИКА 
